
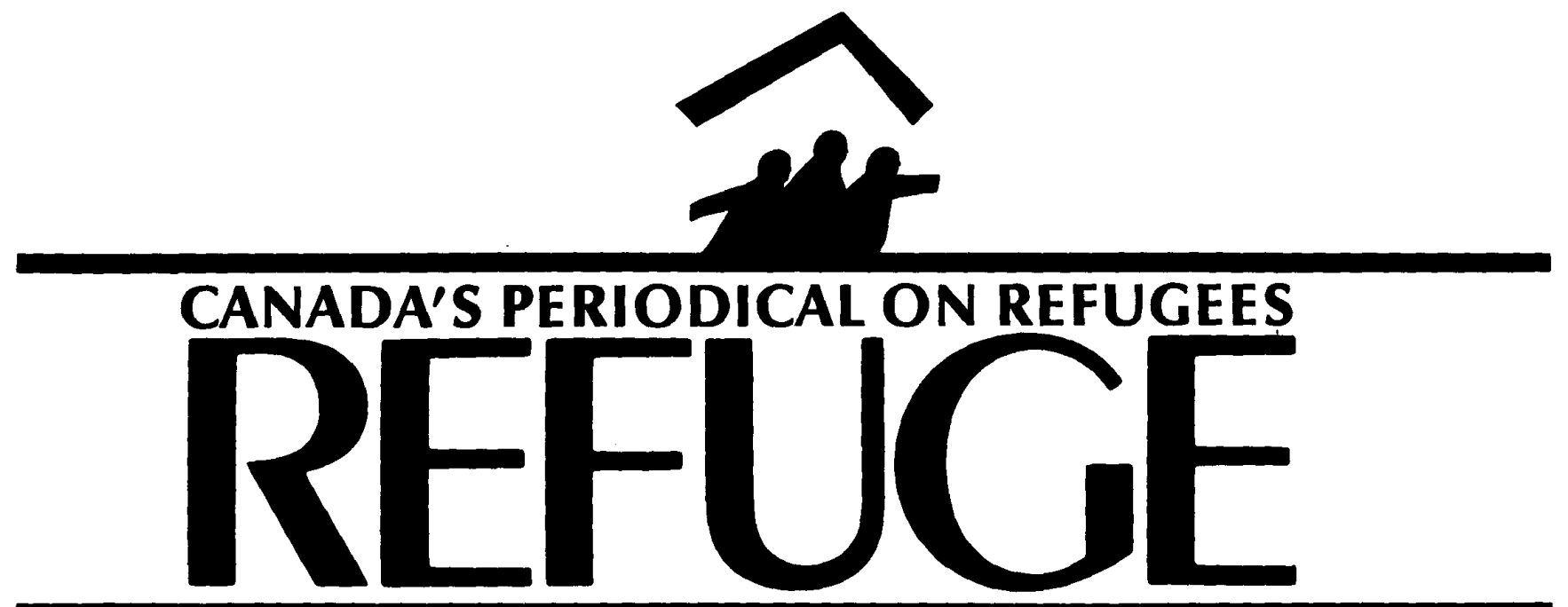

Vol. 6, No. 2

December 1986

\title{
Hope for Refugees in 1987?
}

The New Year traditionally brings forth resolutions of goodwill and generous wishes. The change of calendar eradicates last year's shortcomings and replenishes the emptiness with new hope. Among refugees and their advocates, new hope does not spontaneously arise with turning a calendar leaf. The legacy of past years accumulates.

Nowhere does this legacy more poignantly remind us of unfulfilled hope than in the count of refugees which has continued to increase through the course of the 1980s. Notwithstanding often crude methods of estimation and rounding off counts to the nearest hundred thousand (!), the cumulative impact delivers a heavy blow. In 1983 just under eight million fit the United Nations definition of refugee. That number had relentlessly pushed upward -- nine million in 1984 and ten million by 1985 .

No region has been spared from an increase in refugees. African and Middle Eastern regions, fractured by famine, repressive dictatorships, inter-tribal, ethnic and religious hostilities, have particularly experienced the inevitable consequences for refugee proliferation.

Yet not one Westem resettlement nation has significantly increased intake during this period. With no less relentless monotony, Canada, the United States and Australia ceremoniously have announced

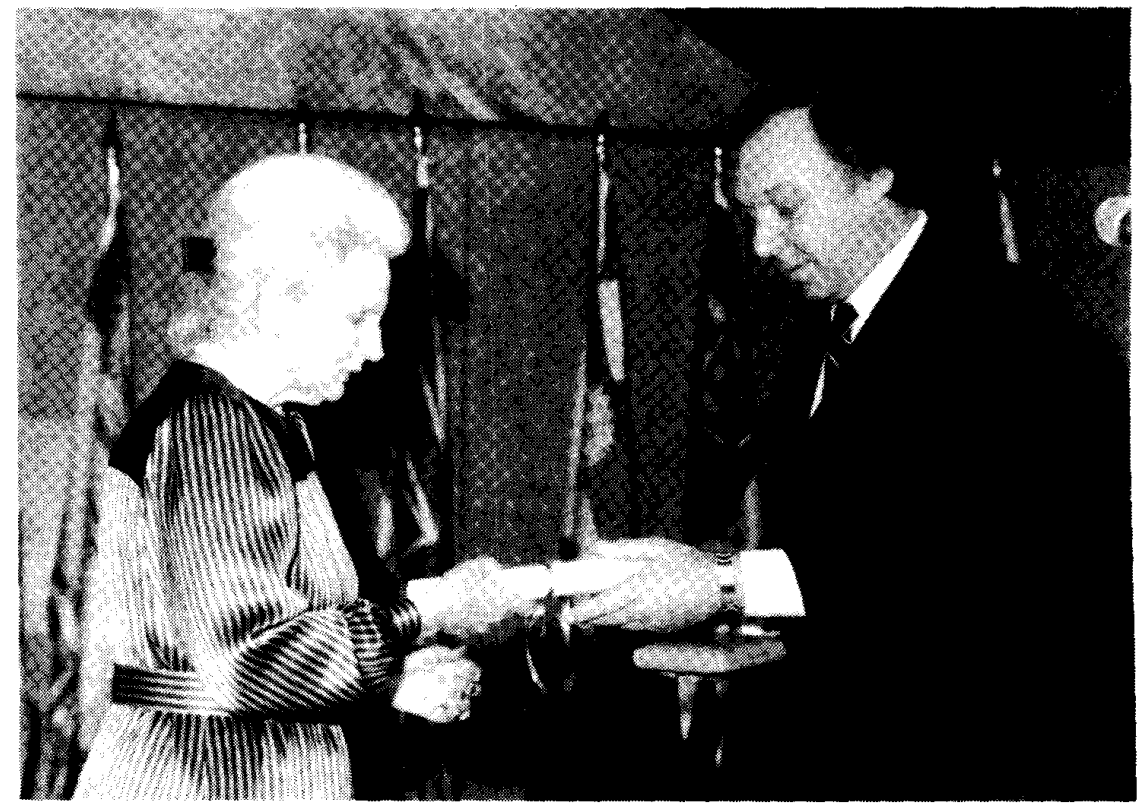

Jeanne Sauvé, Governor General of Canada, accepting, on behalf of the People of Canada, the Nansen Medal from United Nations High Commissioner for Refugees Jean-Pierre Hocké on November 13, 1986.

\section{IN THIS ISSUE:}

First Report on the Host Programme:

Pilot Projects in London, Winnipeg and Regina

Comments on the First Report by C. Michael Lanphier

page 3

Host Programme for Refugee Settlement by Gordon Barnett page 6

Amnesty International and Refugee Reforms by David Matas page 7

A Perspective on Salvadorean Refugees:

Interview with Rubén Zamora

Political Refugees from Peru:

Interview with César Elejalde Estenssoro

page 10

Continued on p. 2 
Hope for Refugees (continued from p. I)

next year's intake to continue at the same level. Projected intake for 1987 for those three countries, including Canada's 12,000 government assisted, reaches only 94,000 refugees. Adding the much lower levels of other Western resettlement countries, the total may reach 100,000 refugees, if all places are filled.

Not only do these nations possess incredible wealth -- in resources, national

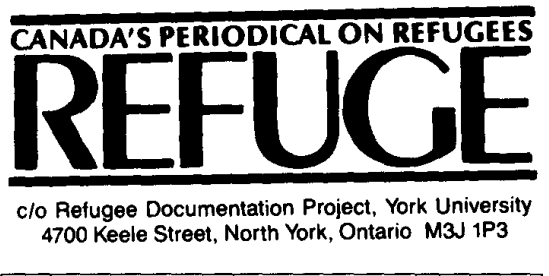

Editor:

C. Michael Lanphier

Feature Editor:

Alex Zisman

Managing Editor:

Noreen Nimmons

Editorial Assistant:

Alice Dinerman

Refuge is dedicated to encouraging assistance to refugees, by providing a forum for sharing information and opinion on Canadian and international issues pertaining to refugees. It is published four times a year by the Refugee Documentation Project. It is a non-profit, independent periodical supported by private donations and by subscriptions. It is a forum for discussion, and the views expressed do not necessarily reflect those of its funders or staff.

All material in Refuge may be reproduced without permission unless copyrighted or otherwise indicated. Credit should be given to the author or source if named.

Subscription rates for one year are $\$ 20.00$. Please enclose payment with your order No discounts can be given for American funds because of bank charges for foreign cheques.

Logo design:

Dreadnaught Cooperative Inc., Toronto

Second Class Mail Registration No. 5512 ISSN 0229-5113 product, and post-industrial technological sophistication -- they are the best informed about the situation of refugees. Govemment ministeries produce lucid and penetrating analyses of upheavals which produce refugees in the first instance and of conditions which turn acute problems into chronic misery. Their region-by-region counts of the number of refugees who could be resettled according to Western standards are well researched. The excellent Canadian report, Refugee Perspectives: 1986-87 estimates over one million refugees in Europe, Southeast Asia and the Middle East; it does not include refugees in Central America, Pakistan or the African continent, as local resettlement is favoured for "solutions" in those regions. Conservatively, another one million from those areas seek resettlement in the West. Such claims have been reinforced by nongovernmental organizations (NGOs) which supplement govern-ment information with on-site reports.

Yet in gratuitous aside, announcements from these same governments simultaneously encourage other nations to "share the burden". Little to proclaim, and even less to hope for!

Were the numbers of refugees in overseas camps an insufficient reminder of the legacy, those seeking recognition inland have increased even more dramatically, although in comparison they number fewer than one-tenth those in camps. Yet every country in Western Europe joins the United States and Canada in clamour for a redress of the increasing "burden".

Again the Western nations have demonstrated keen analyses of the situation. In Canada alone the government has commissioned three reports on (inland) refugee determination since 1980. Responses to these reports from parliamentary and other bodies fill as many pages as do the reports themselves. No question appears more frequently or urgently on agendas of NGO deliberations. Existing procedures for determination are slow, costly and fraught with individual and structural inequalities, as repeatedly documented in Refuge.

At the time of writing, the question of a revised policy for (inland) refugee determination lies before the Cabinet of the Government of Canada. Hopes for an equitable resolution to the complexities of determination are high, as befits the New Year. So too are anxieties, both of wouldbe refugees and their advocates. It is high time to ask how many more deliberations are required before action will be implemented and whether further delay merely complicates one of the most protracted debates in refugee policy.

Is there any news to sustain hope for refugees and their advocates? The report and commentary on the pilot programme on "host family" resettlement in three Canadian cities in these pages points to a vigorous and innovative approach to the recurrent dilemma. Its uniqueness lies in the combination of several well-tried features of resettlement in Canada: among them, government financial support and sustained participation of a small group of Canadian "hosts". The combination fills several gaps; for government-assisted refugees it provided a quicker introduction into everyday Canadian life. Canadian groups can assist without large financial undertaking. And en passant, government and private efforts are united for common endeavour!

On the international scene, refugees and advocates alike are most gratified that Amnesty International is celebrating its 25 th year of distinguished contribution to protection of human rights. Their work is sustained through influential representations not only by advocates but also the concerned public, as described in the article by David Matas in this edition.

So the New Year begins for Canadian refugee interests with an unresolved mix of hope and anxiety. Legacies must be remembered and attended. Nineteen hundred and eighty seven provides us both the occasion and the renewal for the growing tasks.

C. Michael Lanphier

\section{Notice to Our Readers}

Delivery of the October Refuge was delayed by three weeks owing to the temporary loss of the copies in transit from the printer to the mailing house!

We offer our apologies and express assurances that effective measures are now in place to prevent the repetition of such an inconvenience. 